\title{
Self assessed symptoms and risk factors of anemia in urban school going adolescent girls
}

\author{
Kulkarni S.P'. \\ ${ }^{1}$ Dr. Suhas P. Kulkarni, Department of Pediatrics, Dr. D. Y. Patil Medical College, Kolhapur, Maharashtra, India.
}

Address for Correspondence: Dr. Suhas P. Kulkarni, 240, Ruikar Colony, City: Kolhapur, Maharashtra, India. Email: drspk_2000@yahoo.com

\begin{abstract}
Introduction: Anemia prevalence is very high in adolescent girls. Anemia detection is not done adequately due to non specific symptoms. Risk factors for anemia have been identified and taken care of but still the prevalence rate remains same. Methods: A questionnaire based study was conducted at urban school in Kolhapur city in adolescent girls. The questionnaire was filled by the students themselves to find out the symptoms suggestive of anemia. Hemoglobin estimation was done by finger prick method. Results: 81 girls gave consent to the study. The anemia was present in $70.3 \%$ girls, $23 \%$ of the girls had severe anemia. There was no association between symptoms (breathlessness, anorexia, and weakness, lack of concentration, palpitation, giddiness, nails, and edema) and anemia. There was no association between risk factors (worm infestations, education of mother and education of father, menstrual problems) and anemia. In severe anemia cases also there was no association between self assessed symptoms and risk factors and anemia. Conclusion: Prevalence of anemia in adolescent girls remains high. In adolescent girls perception of symptoms of anemia is very poor. Hence there is need to examine hemoglobin concentration actively every year. Education regarding iron rich food should be given. The hemoglobin level of each and every adolescent should be recorded in progress report so as to make students, parents and teachers aware. A hemoglobin day should be observed in the whole country like pulse polio to increase awareness in the community at large.
\end{abstract}

Key words: Adolescent, Anemia, Risk factors, Symptoms

\section{Introduction}

Anemia is a condition in which number of red blood cells and their oxygen carrying capacity is insufficient to meet body's physiological needs [1]. There are many studies regarding anemia in children below 5 years and in pregnant women. There are many programmes for these groups [2]. Surprisingly there are few studies about association of clinical symptoms and signs of anemia in adolescent girls which remain undetected. The prevalence of anemia in adolescent girls varies from $21 \%$ to $69 \%$ in various studies $[3,4]$.

Nutritional needs increase during adolescence in girls which are not taken care of. This leads to various consequences such as stunting. Anemia remains one of the major consequence due to neglect of nutrition in adolescent girls [4]. WHO identifies adolescent from age 10-19 years. The period of adolescence is a period

Manuscript received: $15^{\text {th }}$ March 2017

Reviewed: $24^{\text {th }}$ March 2017

Author Corrected: $30^{\text {th }}$ March 2017

Accepted for Publication: $6^{\text {th }}$ April 2017 of preparation for adulthood [5]. The anemia affects growth of the adolescent girl. It causes decrease in school performance and memory. If the anemia remains untreated later on in pregnancy it can causes fetal mortality, morbidity and increased incidence of low birth weight babies [6].

In India District Kolhapur is having one of the best per capita incomes. Most of the health indicators have improved [7]. Hence there is needed to focus on others parameters such as anemia in adolescent girls.

The symptoms and signs of anemia described in the standard textbook are tiredness, lassitude, easy fatiguability, generalized muscular weakness as the earliest symptoms of anemia. Patient can present as poor feeding, irritability and inadequate school performance. The most characteristic sign of anemia is pallor. Dyspnea on exertion, palpitation is common symptoms [8]. 
The symptoms of anemia develop on two main factors, the rate of development of anemia and state of cardiovascular system of the patient. Symptoms do not usually occur if the development of anemia is slow.

Hence to address this issue of whether the anemia in adolescent girls is developing without symptoms or the symptoms are present but are neglected by the adolescents and parents this study was carried out.

There are studies on symptoms and causes of anemia. But there are few studies about self assessed symptoms of anemia and prevalence of anemia highlighting the importance that anemia can be present without symptoms [8].

\section{Aims and Objectives}

To determine association of self assessed symptoms and risk factors with anemia in adolescent girls.

\section{Materials and Methods}

Study design: Cross sectional study

Setting: This study was carried out by conducting a camp about anemia in an urban school in city of Kolhapur.

Inclusion criteria: Adolescent girls whose parents gave written consent for the study and which are studying in urban school in Kolhapur city.

Exclusion criteria: Adolescent girls who were not willing to participate in the study.

Participants: Girls studying in urban school of Kolhapur city.

Variables: Variables were hemoglobin in gms, symptoms of anemia, and risk factors of anemia

Data source: Questionnaires filled by the adolescent girls studying in urban school and hemoglobin done by finger prick method.
Bias: Since this was a self assessed questionnaire based study and finger prick method was used for hemoglobin estimation bias in detection of cases can be there.

Study size: With the prevalence of anemia around 50\% and considering the alpha $=0.05$ and beta $=0.80$ the sample size is around is around 384 . Hence 350 girls were approached but 81 consented for the study.

Statistical Methods: For the purpose of statistical analysis, those with hemoglobin $<12$ g/dl were categorized as anemia. Association was found out by calculating odds ratio and relative risk was estimated. $\mathrm{P}$ value $<0.05$ was taken as statistically significant.

WHO cut off values of assessing anemia in adolescent girls.

NORMAL: $>12 \mathrm{gm} / \mathrm{dl}$

Mild Anemia: $11 \mathrm{gm}$ to $11.9 \mathrm{gm} / \mathrm{dl}$

Moderate Anemia: $>8$ gm to $<10.9$ gm

Severe Anemia: <8gm/dl [1]

This study was carried out by a questionnaire in Marathi Language. The questionnaire was given a day prior to obtain consent of parents.

It was filled by the students. Verbal assent of the student was taken. The study was approved by the ethical committee.

Haemoglobin concentration was done by finger prick method under aseptic precautions. Data compiled and analyzed after collection of data.

It was coded and entered into Microsoft excel. Association between categorical variables was tested chi-square test and $\mathrm{P}$ value $<0.5$ was taken as significant.

\section{Results}

A cross sectional study was conducted to find out prevalence of anemia, clinical symptoms and associated risk factors among adolescent girls. Total 81 girls took part in study. The percentage of anemia was $70.37 \%$.

Out of 81 girls, 19 girls had severe anemia $23 \%$.

Self assessed symptoms (breathlessness, anemia, weakness, lack of concentration, palpitation, giddiness, nails, edema) did not show any significant association with anemia (table 1). Risk factors worm infestations, education of mother, education of father, menstrual problems did not show any significant association with anemia (Table2). 
Table-1: Association of symptoms with anemia.

\begin{tabular}{|c|c|c|c|c|}
\hline Serial Number & character & Odds ratio & RR & P value* $^{*}$ \\
\hline 1 & Breathlessness & 1.19 & 1.158 & $\mathrm{P}=1.0$ \\
\hline 2 & Anorexia & 1.41 & 1.26 & $\mathrm{P}=0.61$ \\
\hline 3 & weakness & 1.754 & 1.516 & $\mathrm{P}=0.42$ \\
\hline 4 & Lack of concentration & 1.5 & 1.26 & $\mathrm{P}=0.46$ \\
\hline 5 & palpitation & 0.98 & 0.98 & $\mathrm{P}=1.0$ \\
\hline 6 & Giddiness & 0.42 & 0.56 & $\mathrm{P}=0.41$ \\
\hline 7 & Nails & 1.30 & 00 & $\mathrm{P}=1.00$ \\
\hline 8 & Edema & 1.30 & 00 & $\mathrm{P}=1.00$ \\
\hline
\end{tabular}

$*$ p value $<0.05$ significant

Table-2: Association of risk factors with anemia.

\begin{tabular}{|c|c|c|c|c|}
\hline Serial Number & Character & Odds ratio & RR & P value* $^{*}$ \\
\hline 1 & Menstrual problems & 1.736 & 1.684 & $\mathrm{P}=1.00$ \\
\hline 2 & Education(father) & - & - & $\mathrm{P}=0.33$ \\
\hline 3 & Worm infestation & 2.21 & 2.10 & $\mathrm{P}=0.66$ \\
\hline 4 & Education(Mother) & - & - & $\mathrm{P}=0.30$ \\
\hline
\end{tabular}

$* \mathrm{P}$ value $<0.05$ significant

Table-3: Association of self assessed symptoms and severe anemia

\begin{tabular}{|c|c|c|c|c|}
\hline Serial Number & Character & Odds ratio & RR & P value* \\
\hline 1. & breathlessness & - & 0.50 & $\mathrm{P}=0.50$ \\
\hline 2. & anorexia & 0.271 & 0.39 & $\mathrm{P}=0.057$ \\
\hline 3. & weakness & 0.60 & 0.68 & $\mathrm{P}=0.56$ \\
\hline 4. & $\begin{array}{c}\text { Lack of } \\
\text { concentration }\end{array}$ & 0.88 & 0.03 & $\mathrm{P}=0.69$ \\
\hline 5. & Palpitation & 1.47 & 1.39 & $\mathrm{P}=0.66$ \\
\hline 6. & Giddiness & 1.34 & 1.30 & $\mathrm{P}=1.00$ \\
\hline 7. & Edema & 1.05 & - & \\
\hline
\end{tabular}

$* \mathrm{P}$ value $<0.05$ significant

Table-4: Association of risk factors with severe anemia.

\begin{tabular}{|c|c|c|c|c|}
\hline Serial Number & Risk factor & Odds ratio & Relative risk & P value* $^{*}$ \\
\hline 1. & Worm infestation & 1.70 & 1.30 & $\mathrm{P}=0.66$ \\
\hline 2. & Education (father) & & & $\mathrm{P}=0.24$ \\
\hline 3. & Education(Mother) & & & $\mathrm{P}=0.28$ \\
\hline 4. & Menstrual problem & 2.31 & & $\mathrm{P}=0.33$ \\
\hline
\end{tabular}

$* \mathrm{P}$ value $<0.05$ significant

When self assessed symptoms (breathlessness, anorexia, weakness, lack of concentration, palpitation, giddiness, nails, edema) were assessed in severe anemia, still they did not show any association (Table 3). Risk factors like worm infestations, education of mother, education of father, menstrual problems did not show any significant association with severe anemia (table 4). 


\section{Discussion}

Anemia remains a public health concern in developing countries. In our study the percentage of anemia in adolescent girls as found to be $70.37 \%$ which is very high.

Dutta et al 2009 found prevalence of anemia among adolescent girls in rural areas to be $61 \%$. The associated factors were excessive menstruation, worm infestation, history of malaria, vegetarian diet [9]. Sudhagandhi et al observed $52.88 \%$ anemia in adolescents. Mild Anemia, 30.4\%, Moderate Anaemia-37.33\%, no severe Anemia was detected. Anemia in girls was $67.77 \%$ which was similar to our study [10].

Surprisingly anemia was found in $43.52 \%$ girls studying in Medical and Paramedical courses at Ahmadabad [11]. Symptoms and signs significantly associated were palpitations, breathlessness, conjunctival pallor, tongue pallor, nail pallor. But in this study girls were from Medical and Paramedical colleges. In our study participants were urban school going adolescent girls. This may be the reason of lack of association with symptoms

In an urban cross sectional study in Mumbai Vani et al found prevalence Anemia 78.3\% among adolescent girls similar to our study [12]. Study participants were daughters of Government Class IV employees residing in Government Housing Colony of tertiary care hospital in Mumbai, which indicates poor knowledge regarding anemia and Iron rich food .According to Teji $\mathrm{K}$ et al Nutritional status of the adolescent girls was associated with anemia [13].

Angadi et al tried to find out knowledge, attitude and practice about anemia amongst adolescent girls in urban slums, they concluded that good knowledge but poor attitude and practice towards anemia in adolescent girls which may be the reason for persistence of anemia in adolescent girls in urban area [14]. In a hospital based study Thomas et al found Iron, folate and vitamin b12 deficiency in $30.5 \%, 79.5 \%$ and $50 \%$ of adolescent respectively. So they concluded folate, vitamin B12 deficiency are more common in adolescent girls [15]. As this was tertiary care hospital based study vitamin B12 deficiency may have scored more than other deficiencies.

Government in 2012-2013 started weekly Iron and Folic acid supplementation programme. (WIFS) [16] to decrease the high prevalence of anemia in girls and boys. The long term goal was to break the intergenerational cycle of anemia. Malhotra S observed that there was a resistance to uptake of WIFS programme in India. Due to side effects of drugs, negative impact of mass media and failure to learn from earlier successful Public Health Programme [17]. Hema et al found stomach pain in $41 \%$, nausea, vomiting in $24.5 \%$, disliking of tablets $22.3 \%$ in $9^{\text {th }}$ and $10^{\text {th }}$ standard students. Benefits which were observed were improvement in symptoms like reduced fatigue, increased appetite, improved concentration, reduced giddiness and regularization of the menstruation after consuming IFA tablets [18].

Shah et al by a novel way with the help of peer educators at community levels in tribal area gave Iron folic acid supplementation which resulted in $21 \%$ decrease in anemia in adolescent girls [19]. Susheela et al found an inverse relationship in the urine fluoride and Haemoglobin level. The consumption of fluoride may affect adolescent girls adversely. Withdrawal of fluoride from consumption possibly corrected the damage caused to the gastrointestinal mucosa /microvillus which leads to absorption of nutrients including Iron and improvement in anemia [20].

Salam et al did a systematic review of interventions to improve anemia with micro nutrients. Supplementation with Iron, Folic acid, vitamin B12, vitamin A, Zinc, Calcium and Vitamin $\mathrm{D}$ can decrease anemia in adolescent girls. Thus there can be risk factors other than previously thought or there could be appearance of new risk factors yet to be detected [21].

According to BRINDA Project (biomarkers reflecting inflammation and nutritional determinants of anemia) although Iron deficiency is considered to be the most common risk factor micronutrient deficiencies, Vitamin A, Folic acid, Vitamin B12, infections, intestinal parasites, Malaria, HIV and Inherited RBC defect can be associated with anemia. Serum Ferritin level has been considered as primary measure of Iron status.

Anemia can be divided into low inflammatory state and high inflammatory state. Hence inflammatory biomarkers such as Serum Ferritin and Serum transferrin receptors (stfr) may be measured along with nutrient markers. Therefore region wise and country wise programmes should be developed to treat anemia [22]. 
Hence we conclude that Anemia amongst urban adolescent girls in private school remains a major health problem. Perception of symptoms of anemia is very poor by the adolescent girls hence anemia remains undetected and adolescent girls with anemia are not approaching health services for the treatment. Also there may be change in risk factors causing anemia which should be identified and treated accordingly.

Hence there is need to actively examine Haemoglobin concentration of these girls every year. Also there is need to give education regarding iron reach foods and it should be made part of the curriculum. We suggest recording of haemoglobin level of each and every student every year in the Progress Card so as to make the student, parents and teachers aware. Similar to Pulse Polio program, 'A HAEMOGLOBIN DAY' should be observed in all schools on which haemoglobin estimation and IEC activities about anemia should be carried out. Also further research is needed to find out precise causes of anemia in adolescent girls and treated.

Blanket treatment with iron folic acid probably has not resulted in significant improvement in anemia in adolescent girls. Private schools in urban area are probably not covered by the program which should be done.

The Limitations of the study are small sample size, symptoms were not reviewed by physicians and study sample was from single school.

Acknowledgement: We thank Dr. Mrs. Meera Kulkarni for helping to conduct the camp and collection of data from the students.

Funding: Nil, Conflict of interest: None initiated, Perission from IRB: Yes

\section{References}

1. WHO: Hemoglobin concentrations for the diagnosis of anemia and assessment of severity. WHO/ $\mathrm{NMH} /$ $\mathrm{MNH} / 11$-1.www.who.int/vmnis/indicators/ heaemoglobin /en Accessed on 16 march 2017.

2. Policy of control of nutritional anemia .Ministry of health and family welfare, Government of India january1991.www.hetv.org/pdf/anaemia-policy.pdf

3. Shah BK, Gupta P. Anemia in adolescent girls: a preliminary report from semi-urban Nepal. Indian Pediatr. 2002 Dec; 39(12):1126-30.
4. Siva PM, Sobha A, Manjula VD. Prevalence of Anaemia and Its Associated Risk Factors Among Adolescent Girls of Central Kerala. J Clin Diagn Res. 2016 Nov; 10 (11): LC19-LC23. doi: 10.7860 / JCDR /2016 / 20939. 8938. Epub 2016 Nov 1.

5. World Health Organization" Maternal, newborn, child and adolescent health: Adolescent development". URL http://www. who.int/maternal_child_adolescent / topics / adolescence /dev/en. 2015

6. Thame M, Wilks RJ, McFarlane-Anderson N, Bennett FI, Forrester TE. Relationship between maternal nutritional status and infant's weight and body proportions at birth. Eur J Clin Nutr. 1997 Mar; 51 (3):134-8.

7. District level household and facility survey. District fact sheet Kolhapur (2012-13). IIPS Mumbai. https:// nrhm-mis.nic.in/.../state $\% 20$ and $\%$ and 20\% District $\% 20$ Factsheet.

8. Seth T, Hematological disorders. In Ghai OP, Paul VK, Bagga A editors. Ghai Essential Pediatrics seventh ed. New Delhi. CBS Publishers\& Distributors private limited 2009

9. Dutt R, Patil S, Joshi S, Mhatre R and Dev R, Prevalence of anemia among adolescent girls in rural area of Raigad District, Maharashtra, Indian J Prev Soc. Med $2009 ; 40$

10. Sudhagandhi B, Sunderasan S, William WE and Prema A, Prevalence of anemia in the school children of Kattankulathur, Tamil Nadu, India. International Journal Nutrition Pharmacology, Neurological diseases, 2011 Jul 1:1(2):184.

11. Chavda MV, Prajapati JD, Rathod DM, Chaudhary P, Agrawal KM, Screening of novice Adolescent Girls for Anemia studying in Medical and Paramedical Colleges at Civil Hospital Campus, Ahmedabad, Gujarat, India. Natl J Community Med 2013; 4 (2): 337-343.

12. Srinivas V, Mankeshwar R. Prevalence and determinants of nutritional anemia in an urban area among unmarried adolescent girls: A community- based cross-sectional study. International Journal of Medicine and Public Health 2015 Oct 1; 5(4): 283-6. 
13. Teji K, Dessie Y, Assebe T, Abdo M, Anemia and nutritional status of adolescent girls in Babille District, Eastern Ethiopia, Pan African Medical Journal, 2016; 24(1):62 doi:10.11604/pamj.2016.24.62.6949.

14. Angadi N, Ranjitha A, Knowledge, attitude and practice about anemia among adolescent girls in urban slums of Davangere City, Karnataka, International Journal of Medical science and Public Health, 2016 Mar 1; 5: (3):416-20.

15. Thomas D, Chandra J, Sharma S, Jain A, Pemde HK. Determinants of Nutritional Anemia in Adolescents. Indian Pediatr. 2015 Oct; 52(10):867-9.

16. Unicef, The adolescent Girls Anemia Control Programme: Breaking the cycle of Undernutrition in India with a focus on adolescent girls. Briefing paper series: innovations, lessons and good practices. New York, UNICEF. 2011.

17. Malhotra S, Yadav K, Kusuma YS, Sinha S, Yadav $\mathrm{V}$, and Pandav CS Challenges in scaling up successful public health interventions: lessons learnt from resistance to a nationwide roll-out of the weekly ironfolic acid supplementation programmed for adolescents in India.

18. Hema PS, Datta SS, Bahurupi YA, Narayan KA, Ambarasan N, Ramya MR. Factors influencing weekly
IFA supplementation programme (WIFS) among School Children: Where to focus our attention? International Journal of Contemporary Medical Research 2016; 3(4):1075-1079.

19. Shah SP, Shah P, Desai S, Modi D, Desai G, Arora H. Effectiveness and Feasibility of Weekly Iron and Folic Acid Supplementation to Adolescent Girls and Boys through Peer Educators at Community Level in the Tribal Area of Gujarat. Indian J Community Med. 2016 Apr-Jun;41(2):158-61. doi: 10.4103/0970-0218. 173498.

20. Susheela AK, Gupta R, Mondal NK, Anemia in adolescent girls: An intervention of diet editing and counseling. The National Medical Journal India 2016 Jul 1;29(4):200-4.

21. Salam RA, Hooda M, Das JK, Arshad A, Lassi ZS, Middleton $\mathrm{P}$, Bhutta ZA. Interventions to improve adolescent nutrition: A systematic review and meta analysis. J Adolesc Health. 2016 Oct;59(4S):S29-S39. doi: 10.1016/j.jadohealth. 2016.06.022.

22. Suchdev PS, Namaste SML, Aaron GJ, Raiten DJ, Brown KH, Flores-Ayala R, BRINDA Working Group. Overview of the biomarkers reflecting inflammation and nutritional determinants of anemia (BRINDA) Project. Advance in Nutrition: An international Review Journal. 2016 Mar 1; 7(2):349-56.

\section{How to cite this article?}

Kulkarni S.P. Self assessed symptoms and risk factors of anemia in urban school going adolescent girls. J PediatrRes.2017;4(04):247-252.doi:10.17511/ijpr.2017.04.01. 